\title{
Pattern of Disease among patient attending in Outpatient Department in a Tertiary Hospital
}

Dr. Monika Roy ${ }^{1 *}$, Dr. Sushanta Kumar Barman ${ }^{2}$, Dr. Muhammad Ehasun Uddin Khan ${ }^{3}$, Dr. Priobrata Karmakar ${ }^{4}$, Dr. Muhammad Anamul Hoque ${ }^{5}$, Dr. Purabi Barman ${ }^{6}$, Dr. Ratindra Nath Mondol ${ }^{7}$

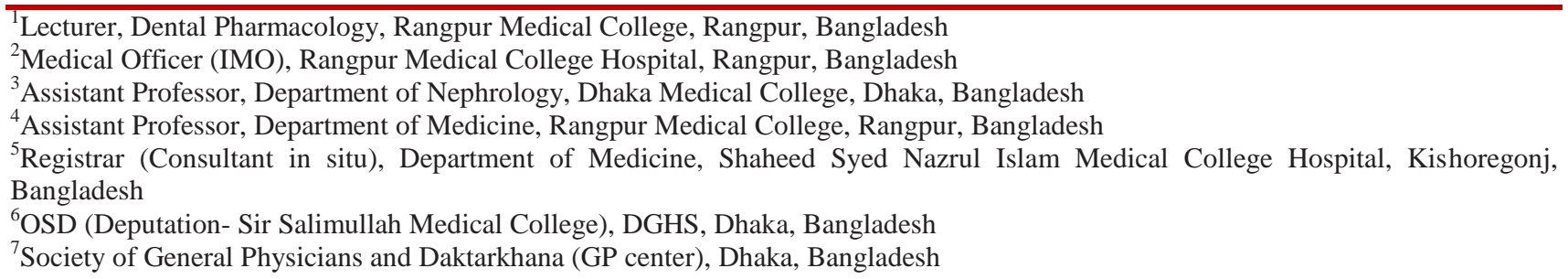

DOI: $\underline{10.36347 / \text { sjams.2021.v09i04.016 }}$

| Received: 08.03.2021 | Accepted: 06.04.2021 | Published: 18.04.2021

*Corresponding author: Monika Roy

Abstract Original Research Article

Objective: To find out the common diseases in which antibiotics are used among patients of outpatient department of Dhaka Medical College \& Hospital. Method: This Observational Cross-sectional Descriptive study was conducted in in outpatient department of Medicine, Surgery, Gynaecology and Obstetrics of Dhaka medical college \& Hospital. Later the study was compiled in the Department of Pharmacology, Dhaka Medical College. Total study period was one year extending from January, 2019 to December Patients in outpatient department of Medicine, Surgery, Gynaecology and Obstetrics of Dhaka Medical College \& Hospital. Result: This study was carried out to determine the common antibiotics \& diseases in which antibiotics are used among patient in outpatient department of a tertiary care hospital. A total 2404 prescriptions was screened in this study, among 600 prescriptions containing antibiotics purposively selected according to inclusion and exclusion criteria from different outpatient of Medicine, Surgery and Gynaecology \& Obstetrics department of Dhaka Medical College and Hospital to reach the end of the study. Conclusion: The disease burden of Bangladesh is moving from communicable to non-communicable diseases the major causes of morbidity and mortality in our country are infective diseases and therefore antibiotics are the most widely used group of medicine.

Keyword: Disease, ,Antibioticmicroorganisms, prescriptions, bacterial resistance.

Copyright $\odot 2021$ The Author(s): This is an open-access article distributed under the terms of the Creative Commons Attribution 4.0 International License (CC BY-NC 4.0) which permits unrestricted use, distribution, and reproduction in any medium for non-commercial use provided the original author and source are credited.

\section{INTRODUCTION}

The history of advancement of modern medicine must include the inventions in the field of antimicrobial chemotherapeutics. 'Bacteria invented antibiotics billions of years ago.[1] Among medicines antibiotics are used to prevent and treat bacterial infections. As infections are the major reason for the poor prognosis of a condition, proper control of infections can prevent certain co-morbid or morbid situations. It is known that a coin has two sides; just like that antibiotics also have two sided effects. One is control of infection; the other is the resistance of an organism. [2]
Prescription with antibiotics is mostly made on empirical basis and broad-spectrum. This is influenced by interplay of the knowledge, expectations of prescribers and patients, economic incentives, characteristics of a country's health system and the regulatory authority. Patient-related factors those enforce inappropriate antibiotic use are belief and perception towards medication and non-adherence to treatment. In addition, poor education, absence of guideline, lack of resources, poor training, patient load and inaccessibility of antibiotics can cause irrational use of antibiotics. This inappropriate antibiotic use leads to adverse drug effects, increase cost, increase the mortality and the morbidity and emergence of resistance. [3] 
Drug utilization study is a process of medical audit that involves monitoring and evaluation of the prescribing patterns of drug and also helps to modify the prescribing practices to achieve rational therapeutic use as well as to prevent the economic load which will improve health care system. Therefore, monitoring and evaluation of prescribing patterns of antimicrobial agents are one of the recommended techniques to control resistance and also to improve the prescribing practices. [4]

A study done in Chittagong Medical College Hospital and Chattagram Ma-O- Shishu Hospital showed that microbes causing Hospital acquired infections are commonly found in the environment of healthcare infrastructure in Bangladesh. These microbes also show different levels of susceptibility to antibiotics commonly used in Bangladesh. The common microbes identified are Gram positive Streptococcus, S. aureas, coagulase negative Staphylococcus, Gram negative Pseudomonas and Serratia. Almost all of these microbes show resistance to cefipime, a fourth generation of cephalosporin. However, ciprofloxacin and vancomycin shows to be most effective against the above identified bacteria. [5]

Another study on stool samples were collected from diarrhoeal patients attended the Sheikh Hasina Medical College and Hospital, Tangail. 31\% were positive for both ETEC and EPEC strains, $23 \%$ were positive for ETEC strains, and $8 \%$ were positive for EPEC strains. It was detected that $82.60 \%, 65.21 \%$, $73.91 \%, 78.26 \%, 47.82 \%, 60.86 \%$, and $47.82 \%$ of ETEC strains were resistant to amoxicillin-clavulanic acid (AMC), tetracycline (TE), nalidixic acid (NA), azithromycin, ciprofloxacin, ampicillin (AMP), and erythromycin (E), respectively. Whereas it was detected that $87.5 \%$ EPEC strains were resistant to AMC, AMP, and E, 75\% EPEC strains were resistant to TE and NA, respectively. Both strains developed multidrug resistance to commonly prescribed antibiotics. [6]

Bangladesh has achieved promising progress in the manufacturing of quality medicine after the promulgation of Drug (Control) Ordinance-1982. As a consequence, Bangladesh is now exporting their quality medicine to near about 80 foreign countries, but the total health care system in this country has not reached to the desirable stage. A lot of factors provoking the situation worsen day by day. One of the major causes is the prescription errors. [7]

Almost half of all medicines globally are used irrationally. Medicine experts in WHO say irrationality can have severe consequences: adverse drug reactions, drug resistance, protracted illness and even death. In addition, the financial cost incurred by individuals and governments due to irrational use is unnecessary and often extremely high, particularly in developing countries where patients often pay for medicines out of pocket. Irrational use of medicines includes over treatment of a mild illness, inadequate treatment of a serious illness, misuse of anti-infective drugs, over-use of injections, self-medication of prescription drugs and premature interruption of treatment. Data from many countries show that such practices are frequent, and not exclusive to developing countries (WHO, 2014). [8]

Dynamic online antimicrobial guideline with stewardship program was attempted in Bangabandhu Sheikh Mujib Medical University (BSMMU) to improve the antimicrobial prescribing. [9]

\section{ОВJECTIVE}

General objective:

- To find out the common antibiotics \& diseases in which antibiotics are used among patients of outpatient department of Dhaka Medical College \& Hospital.

\section{:Specific objectives}

- To observe the antibiotics used empirically and/or definitivly among patients of outpatient department of Dhaka Medical College \& Hospital.

- To see whether the antibiotics used are based on updated BSMMU guidelines.

\section{Methodology}

\section{Sample selection criteria \\ Inclusion criteria:}

- $\quad$ Patients of both gender and aged $>18$ years.
- Patients attending outpatient department of (Medicine, Surgery and Gynaecology \& Obstetrics) of Dhaka Medical College and Hospital.

- Patients who are prescribed with antibiotics.

- Patients who are willing to give consent. 
Exclusion criteria:

:Following patients were excluded from the study

- Patients of either gender and aged <18 years.

- Patients' needs admission on inpatient department of (Medicine, Surgery, \& Gynaecology \& Obstetrics) of Dhaka Medical College and Hospital.

- Patients who are not prescribed with antibiotics.

- Patients who are not willing to give consent.

\section{Sample Size:}

know, $\mathrm{n} \mathrm{We}=\frac{\mathrm{z}^{2 \mathrm{pq}}}{\mathrm{d}^{2}}$

,Where, For highest sample size determination we took $\mathrm{p}=$ Expected proportion of event/Prevalence or proportion of occurance $=0.5$

$0.5=0.5-\mathrm{p}=1-\mathrm{q}=1$

$\mathrm{d}=$ Acceptable error $=0.05$

$\mathrm{Z}=1.96$ at $95 \%$ confidence interval

$\mathrm{n}, \mathrm{So}=\frac{\mathrm{z}^{2 \mathrm{pq}}}{\mathrm{d}^{2}} \mathrm{n}=\frac{1.96 \times 1.96 \times 0.5 \times 0.5}{0.05 \times 0.05} 384=$

According to the manual titled "How to investigate drug use in health facilities", minimum encounters for a cross sectional survey is 600 (WHO, 1993). So, for this study, I shall include 600 prescriptions from outpatient department (Medicine,

(urgery\&Gynaecology and obstetricsSof Dhaka Medical College \& Hospital.

\section{Data Collection Instruments and Procedure:}

After taking verbal consents from the patients attended in outpatient medicine department of Dhaka Medical College and Hospital, the prescriptions were seen and sorted whether prescription contained antibiotic or not. If the prescription had no antibiotic then it was recorded in data collection form as an entry only to be utilized to calculate the proportion of antibiotic prescribing. If prescription contained antibiotic then written informed consent was taken from patient and the picture of those prescriptions were captured by a photo capturing device. Later on, the photo of antibiotic containing prescription was screened and reviewed to record in the data collection form.

\section{RESULT}

Demographic Characteristics of the Study Patients Age Distribution of Study Patients

Table-1: Distribution of study patients by age in years $(N=600)$

\begin{tabular}{|l|l|l|}
\hline $\begin{array}{l}\text { Age range of } \\
\text { respondents }\end{array}$ & Frequency & Percentage \\
\hline$\leq 20$ & 63 & 10.5 \\
\hline $21-40$ & 445 & 74.1 \\
\hline $41-60$ & 81 & 13.5 \\
\hline $61-80$ & 11 & 1.9 \\
\hline $\begin{array}{l}\text { Mean } \pm \text { SD } \\
\text { (Range) }\end{array}$ & $\begin{array}{l}31.80 \pm 10.92 \\
(20-43)\end{array}$ \\
\hline
\end{tabular}

Table-1; illustrates that the highest antibiotic usage age group was 21-40 years which occupied 445 (74.1\%), followed by 41-60 years 81(13.5\%), $\leq 20$ years 63

$(10.5 \%)$ and the lowest age group 61-80 years

$11(1.9 \%)$. Minimum age of patients of this study was 18 years, Maximum age of this study was 77 years. The mean age was 31.80 years and SD was 10.92 years.

\section{Monthly Income and Educational Status of Study Patients}

Table-2: Distribution of monthly income of study patients $(\mathrm{N}=600)$

\begin{tabular}{|l|l|l|}
\hline Variable & Frequency & Percentage \\
\hline Monthly Income \\
\hline Range in taka \\
\hline$\leq 20,000$ & 460 & 76.7 \\
\hline $20,001-40,000$ & 121 & 20.2 \\
\hline$>40,000$ & 19 & 3.1 \\
\hline Educational status & 128 & 21.3 \\
\hline Illiterate & 29.1 \\
\hline Primary education & 175 & 23.6 \\
\hline Below SSC & 142 & 14.8 \\
\hline Below HSC & 89 & 5.8 \\
\hline Graduate & 35 & 5.4 \\
\hline Post-graduate & 31 & P
\end{tabular}

Table-2: shows that 460 (76.7\%) study patients earned $\leq 20,000$ taka monthly, $121(20.2 \%)$ earned 20,00140,000 and $19(3.1 \%)$ earned $>40,000$ taka monthly. Most of patient's monthly income below 20, 000 taka.

Most of Patients were primary educated (29.1\%).

Table-3: Department wise distribution of study subjects receiving antibiotics $(\mathrm{N}=600)$

\begin{tabular}{|l|l|l|}
\hline Name of outpatient & Patient attend & Prescribed antibiotic \\
\hline Department & Number (Percentages) & Number (Percentages) \\
\hline Medicine & $625(26.0 \%)$ & $200(32.0 \%)$ \\
\hline Surgery & $704(29.2 \%)$ & $200(28.4 \%)$ \\
\hline Gynaecology \& Obstetrics & $1075(44.8 \%)$ & $200(18.6 \%)$ \\
\hline Total & $2404(100 \%)$ & $600(24.9 \%)$ \\
\hline
\end{tabular}

In this study $24.9 \%$ Patients of outpatient department received antibiotic. Among them Medicine was (32\%), Surgery was (28.4\%), Gynecology \& obstetrics was
$(18.6 \%)$. Most of prescribed antibiotics were in Medicine outpatient department. 


\section{Duration of Antibiotic Therapy}

Table-4: Department wise and Proportion of Duration of antibiotic therapy $(\mathrm{N}=600)$

\begin{tabular}{|l|l|l|l|l|}
\hline Duration & Medicine & Surgery & Gynaecology \& Obstetrics & Total \\
\hline$($ Days $)$ & $\mathrm{n}(\%)$ & $\mathrm{n}(\%)$ & $\mathrm{n}(\%)$ & $\mathrm{n}(\%)$ \\
\hline$\leq 3$ & $1(0.5 \%)$ & $1(0.5 \%)$ & $0(0 \%)$ & $2(0.3 \%)$ \\
\hline $4-7$ & $179(89.5 \%)$ & $167(83.5 \%)$ & $119(59.5 \%)$ & $465(77.5 \%)$ \\
\hline $8-14$ & $20(10.0 \%)$ & $32(16 \%)$ & $76(38 \%)$ & $128(21.4 \%)$ \\
\hline$>14$ & $0(0.0 \%)$ & $0(0 \%)$ & $5(2.5 \%)$ & $5(0.8 \%)$ \\
\hline Total & $200(100 \%)$ & $200(100 \%)$ & $200(100 \%)$ & $600(100 \%)$ \\
\hline
\end{tabular}

Table-4: shows that the highest duration of antibiotic therapy was 4-7days 465 (77.5\%) followed by 8 - 14 days 128 $(21.4 \%), \leq 3$ days $2(0.3 \%)$ and $>14$ days $5(0.8 \%)$.

\section{Medical Conditions in Outpatient Department (OPD) Where Antibiotics Were Used}

Table-5: Medical conditions in Medicine OPD where antibiotics were used $(\mathbf{n}=\mathbf{2 0 0})$

\begin{tabular}{|l|l|l|}
\hline Name of diseases & Frequency & Percentage \\
\hline $\begin{array}{l}\text { Respiratory tract } \\
\text { infections }\end{array}$ & 115 & 57.5 \\
\hline Pharyngitis & 26 & 13.0 \\
\hline Enteric fever & 21 & 10.5 \\
\hline Urinary tract infections & 12 & 6.0 \\
\hline Gastroenteritis & 22 & 11.0 \\
\hline $\begin{array}{l}\text { Skin and soft tissue } \\
\text { infections }\end{array}$ & 4 & 2.0 \\
\hline Total & 200 & 100 \\
\hline
\end{tabular}

Table-5: shows, In medicine OPD respiratory tract infections $115(57.5 \%)$ is most common disease where antibiotics used followed by pharyngitis $26(13 \%)$, gastroenteritis $22(11 \%)$, enteric fever $21(10.5 \%)$, urinary tract infections $12(6 \%)$, skin and soft tissue infections $4(2 \%)$ respectively.

Table-6: Proportion of medical conditions in gynaecology OPD where antibiotics were used (continued) $(\mathbf{n}=\mathbf{2 0 0})$

\begin{tabular}{|l|l|l|}
\hline Name of diseases & Frequency & Percentage \\
\hline $\begin{array}{l}\text { Pelvic inflammatory } \\
\text { disease }\end{array}$ & 83 & 41.5 \\
\hline Valvovaginitis & 64 & 32.0 \\
\hline Urinary tract infections & 46 & 23.0 \\
\hline Bartholin abscess & 7 & 3.5 \\
\hline Total & 200 & 100 \\
\hline
\end{tabular}

Table-6: shows that among Gynaecology OPD, pelvic inflammatory disease $83(41.5 \%)$ is most common conditions where antibiotics are used followed by, valvovaginitis $64(32 \%)$, urinary tract infections 46 (23\%), bartholin abscess 7 (3.5\%) respectively.
Table-7: Proportion of medical conditions in Surgery OPD where antibiotics were used (continued) $(\mathbf{n}=\mathbf{2 0 0})$

\begin{tabular}{|l|l|l|}
\hline Name of diseases & Frequency & Percentages \\
\hline Abscess & 62 & 31.0 \\
\hline Cellulitis & 26 & 13.0 \\
\hline Wound infections & 26 & 13.0 \\
\hline Paronychia & 25 & 12.5 \\
\hline Boil & 23 & 11.5 \\
\hline Infected cysts & 19 & 9.5 \\
\hline $\begin{array}{l}\text { Urinary tract } \\
\text { infections }\end{array}$ & 10 & 5.0 \\
\hline Diabetic foot & 9 & 4.5 \\
\hline Total & $\mathbf{2 0 0}$ & $\mathbf{1 0 0}$ \\
\hline
\end{tabular}

Table-7: shows, in surgery wards abscess $62(31 \%)$ were most common diseases where antibiotics used followed by cellulitis $26(13 \%)$, wound infections $26(13 \%)$, paronychia $25(12.5 \%)$, boil $23(11.5 \%)$, infected cysts $19(9.5 \%)$, urinary tract infections $10(5 \%)$, diabetic foot $9(4.5 \%)$ respectively.

\section{DISCUSSION}

In this study the demographic profile showed the predominant age group of this study was 21-40 years $(74.1 \%)$, which was similar to the study, conducted in Assam, India 21-40 years age group (53\%), (Bhagawati, Kakati and Thakuria, 2017) [10] and Kolkata, India, where predominant age group was 25-30 years (Manab et al., 2017). The reason of this finding may be the younger patients are more concerned about illness. [11]

The highest income range of this study was $\leq 20,000 \mathrm{Tk}(76.7 \%)$, which is may indicate the low economic group of people who mainly visited the Govt. hospitals. The patients attended in outpatient department of DMCH were mostly educated by primary (29.1\%) followed by below SSC (23.6\%). The reasons of this educational status may be poverty and lack of social awareness of our population. 
In this study $86 \%$ prescribed antibiotics were in oral formulation as a single route in OPD of surgery, medicine and gynaecology department. This was similar to Manab, et al., 2017, Kumar, et al., 2010 where prescribed oral formulation of antibiotics were $98 \%$ and $94.94 \%$ respectively. $[11,12]$

In this study, 97\% prescriptions were prescribed as an empirical therapy. Similar findings were found to a study done by Ahmed, et al., 2015, where empirical therapy in tertiary health care center was $93.5 \%$. [13]

The most common disease in the current study for which antibiotics were prescribed in Medicine OPD predominantly was respiratory tract infection (RTI) $(57.5 \%)$ which was similar to a study done by Laizu, et $a l ., 2018$ where respiratory tract infection (RTI) (32\%) was most common indications. This was also found by Ahmed, et al., 2015.[13]

In Gynaecology OPD most common indication of antibiotic prescription was pelvic inflammatory disease $(41.5 \%)$ which was similar to a study done in Eastern India by Manab, et al., 2017 where most common prescribed disease was pelvic inflammatory disease (41.4\%).[11] Pelvic inflammatory disease is most common prevalent disease in subcontinent. Almost of all antibiotics were prescribed without doing any culture and sensitivity.

In this study there were $39.2 \%$ encounters containing inappropriate choice of first antibiotic therapy (neither used preferred or alternative antibiotics). A study conducted in Indonesia where inappropriate selection of antibiotic $22.7 \%$ (Andrajati, et al., 2016) as like as this study. [14]

The adherence to guideline was $67.5 \%$ in current study. Similar findings were found to a study done by sultana, et al., 2015 in BSMMU that there more than 80 percent was adherent to BSMMU guideline. These rational uses of antibiotics decrease antibiotics resistance. The study also urges the physician to be more professional and careful when antibiotic is prescribed for the outpatients.

\section{LIMITATIONS OF THE STUDY}

This study had the following limitations:

1) Rationality of antibiotic use was not assessed in this study due to lack of national antibiotic guideline.

2) The adverse antibiotic reactions could not be collected due to limited time frame.

3) This study was done in a tertiary care hospital having well communication; however, conditions might be worse in the remote corners of Bangladesh.

\section{RECOMMENDATIONS}

The following recommendations are forwarded in regard to this study:

1) Use of antibiotic therapy should be evidencebased.

2) Educational awareness program can be arranged and further monitoring of antibiotic utilization pattern can be carried out to assess the improvement of the intervention.

3) Formulation of national antibiotic guideline or institutional antibiotic guideline.

4) Formulation of Hospital Antibiotic Policy in order to subdue the multidrug resistant organisms.

\section{CONCLUSION}

From this study we can conclude that disease burden of Bangladesh is moving from communicable to non-communicable diseases the major causes of morbidity and mortality in our country are infective diseases and therefore antibiotics are the most widely used group of medicine.

\section{REFERENCES}

1. Huang SM, Lertora JJ, Markey SP, Atkinson Jr AJ, editors. Principles of clinical pharmacology. Academic Press; 2012 Sep 18.

2. Gowthami B, Spurthi T. Drug utilization evaluation of antibiotics in general medicine department of a tertiary care hospital. Value in Health. 2016 Nov 1; 19(7):A824

3. Getachew E, Aragaw S, Adissie W, Agalu A. Antibiotic prescribing pattern in a referral hospital in Ethiopia. African Journal of Pharmacy and Pharmacology. 2013 Oct 15; 7(38):2657-61.

4. NAJMI A, VERMA A, AIMAN U. Drug utilization study in the outpatient pediatric department of a tertiary care teaching hospital of district Lucknow. Asian J Pharm Clin Res. 2015; 8(3):327-30.

5. Ira NI, Marjana N, Mollah AK. Antibiotic Resistance Bacteria in Tertiary Hospitals in Chittagong, Bangladesh. Int. J. Sci. Eng. Sci. 2019; 3: $18-21$.

6. Rahman MS, Huda S. Antimicrobial resistance and related issues: An overview of Bangladesh situation. ||| Bangladesh Journal of Pharmacology|||. 2014 May 11; 9(2):218-24.

7. Ata M, Hoque R, Biswas RS, Mostafa A, Hasan FU, Barua HR. Antibiotics prescribing pattern at outpatient department of a tertiary medical college hospital. Chattagram Maa-O-Shishu Hospital Medical College Journal. 2018; 17(2):36-9.

8. World Health Organization. Antimicrobial resistance: global report on surveillance. World Health Organization; 2014. Available at. htttps;//apps.who.int/iris/ bitstream/handle/10665/112642/eng.pdf 
9. Sultana F, Rahman A, Paul TR, Sarwar MS, Islam MA, Rashid M. Prescribing pattern and prescription errors: a study at a tertiary care hospital of Bangladesh. Bangladesh Pharmaceutical Journal. 2015 Jun 1; 18(1):20-4.

10. Bhagawati R, Bhagawati K, Jini D, Alone RA, Singh R, Chandra A, Makdoh B, Sen A, Shukla KK. Review on climate change and its impact on agriculture of Arunachal Pradesh in the Northeastern Himalayan region of India. Nature Environment and Pollution Technology. 2017 Jun $1 ; 16(2): 535$.

11. Manab N, Pragnadyuti M , Tithishri K, Rani G, Suhrita P. Antibiotic Utilization Pattern in Gynecology Out-Patient Department of a Tertiary Care Centre in Eastern India. Saudi J. Med. Pharm. Sci. 2017: 3: 796-799.
12. Kumar J, Shaik MM, Kathi MC, Deka A, Gambhir SS. Prescribing indicators and pattern of use of antibiotics among medical outpatients in a teaching hospital of Central Nepal. Journal of College of Medical Sciences-Nepal. 2010; 6(2):7-13.

13. Ahmed AA, Jilani MS, Chowdhury OA, Islam KS, Hossian MA, Alam MJ, Siddique MA, Barai L, Rahman F, Haq JA. Use of antibiotics in selected tertiary and primary level health care centers of Bangladesh. Ibrahim Medical College Journal. 2015; 9(2):42-4.

14. Andrajati R, Tilaqza A, Supardi S. Factors related to rational antibiotic prescriptions in community health centers in Depok City, Indonesia. Journal of infection and public health. 2017 Jan 1; 10(1):41-8. 